\title{
Cooling Arrangements for Hybrid Thermal-CPV Receivers with High Output Coolant Temperature for Combined Electricity Generation and Water Desalination
}

\author{
Mohamed Omri $\mathbb{C}^{1},{ }^{1}$ Yusuf Al-turki, ${ }^{2}$ Étienne Léveillé, ${ }^{3}$ Richard Arès, ${ }^{3}$ and Luc Fréchette $\mathbb{C}^{3}$ \\ ${ }^{1}$ King Abdulaziz University, Deanship of Scientific Research, Jeddah, Saudi Arabia \\ ${ }^{2}$ King Abdulaziz University, Electrical and Computer Engineering Department, Jeddah, Saudi Arabia \\ ${ }^{3}$ Université de Sherbrooke, \\ Interdisciplinary Institute for Technological Innovation (3IT) and Department of Mechanical Engineering, Quebec City, Canada
}

Correspondence should be addressed to Mohamed Omri; mnomri@kau.edu.sa

Received 15 April 2021; Revised 29 April 2021; Accepted 15 May 2021; Published 7 June 2021

Academic Editor: Ahmed Mostafa Khalil

Copyright (c) 2021 Mohamed Omri et al. This is an open access article distributed under the Creative Commons Attribution License, which permits unrestricted use, distribution, and reproduction in any medium, provided the original work is properly cited.

\begin{abstract}
Human civilization uses vast quantities of water and electricity. Natural fresh water is in short supply in many regions, and the shortfall is increasingly filled through energy-intensive desalination. Electricity still largely comes from burning fossil fuels, resulting in $\mathrm{CO}_{2}$ emissions. Concentrator photovoltaics (CPV) can provide not only electricity but also heat from cooling of the $\mathrm{CPV}$ cells, providing additional energy for thermally driven processes such as desalination. This paper evaluates a CPV receiver cooling arrangement for linear CPV systems which maximizes electricity production for a given CPV cell area while supplying heat byproduct boosted to a temperature higher than the temperature of the fluid that cools the CPV cells, increasing the range of processes to which the heat can be applied.
\end{abstract}

\section{Introduction}

Water is a necessity for all life, and human civilization uses vast quantities of water for food production and industry as well as for domestic use. In the Kingdom of Saudi Arabia (KSA), food production (crops plus grazing) uses over $80 \%$ of the total water consumed [1]; the Kingdom still imports more than $80 \%$ of the food it consumes [2] (with water availability being a limiting factor), so KSA could use far more water if more were available. With the Kingdom having minimal surface water, and with ground water being depleted, KSA is dependent on desalination, which already provides $\sim 70 \%$ of the Kingdom's water and is growing at $14 \%$ per year [1].

Electricity has become essential for modern life, but electricity often comes from combustion of fossil fuels, with $\mathrm{CO}_{2}$ emitted being a major contributor to global warming.
Even in regions without significant hydroelectricity, water and electricity are intertwined; water is used to cool power plants, heat from fossil-fuel-fired power plants is used to run thermal desalination, and electricity is used to run reverse osmosis desalination. In KSA, $15 \%$ of electricity is used for desalination [3]. Most regions that are significant users of desalination (e.g., KSA, UAE, and south-western USA) have plentiful sunlight, and both electricity generation and desalination can be powered by solar energy, either solar thermal or photovoltaic/reverse osmosis.

Reverse osmosis is extremely efficient for producing fresh water from low-salt brackish water, but the more salt that is present, the more electricity is needed to force water through the semipermeable membrane against osmotic pressure. Membrane fouling is a significant issue, and salt water often requires extensive pretreatment, including adding acids and flocculants and having multiple filtration stages [4]. 


\section{Photovoltaic/Thermal Hybrids}

Thermal desalination requires more energy than reverse osmosis to produce a given amount of fresh water, but most of the energy needed is in the form of low-grade heat rather than valuable electricity. Photovoltaic (PV) systems produce low-grade heat as a waste product, and PV works best when cool, so hybridizing the PV and thermal systems can both cool the PV and heat water, benefiting both the PV and the thermal subsystems. Pairing PV with thermal desalination is thus potentially a win-win combination.

Wang et al. propose adapting flat PV panels to provide the heat to drive multistage membrane distillation (MSMD) and obtained $1.82 \mathrm{~kg} / \mathrm{m}^{2} /$ hour under 1-sun illumination with three membrane distillation stages [5]. The MSMD device of Wang et al. is a promising direction but would need modifications in order to be affordable; for example, the MSMD device uses aluminum nitride for a heat conduction layer due to its high thermal conductivity and its corrosion resistance in salt water, but aluminum nitride is quite expensive, so panel-sized areas would be prohibitively costly.

Wang et al. also acknowledge that higher saltwater temperatures drive more fresh water production per amount of heat but that higher cell temperatures increase heat loss from the cells themselves and thus reduce heat available for desalination and that this heat loss is largely proportional to cell area. Concentrating the solar energy through lenses or mirrors reduces both the PV area and the thermal energyabsorption area needed, thereby reducing the heat loss even at higher temperatures.

Numerous types of concentrator PV with thermal capture (CPV-T) have been explored for desalination. In 2007, Mittelman et al. [6] evaluated both low-concentration CPV-T using silicon concentrator PV cells and high-concentration CPV-T using triple-junction concentrator PV cells and mapped out the collector cost versus electricity cost at which CPV-T with multieffect evaporation desalinates water at lower cost than reverse osmosis. They also compare $\mathrm{CPV}-\mathrm{T}$ to thermal-only parabolic trough concentrators (PTC) and conclude that "all options based on PV collectors are better than the option of thermal-only collectors (PTC) as long as their installed cost is less than $\$ 4 / \mathrm{Wp}$, which is easily reached by all $\mathrm{PV}$ technologies according to the available estimates" [6].

While CPV-T for thermal desalination can use a wide variety of concentration mechanisms, parabolic troughs are a well-established technology and can supply heat with thermal efficiency $>75 \%$ over a wide range of conditions [7], including at temperatures suitable for thermal desalination (MED and MSF). Parabolic troughs also scale well from a single trough of a few tens of square meters [8], suitable for off-grid use, to vast fields that supply hundreds of megawatts to thermal powerplants to feed the grid [9]. Off-grid locations have high electricity costs and desalination costs and so present an entry point to establish solar desalination (whether CPV-T or PV with reverse osmosis), and replacing fossil-fuel-driven thermoelectric plants that are accompanied by thermal desalination would use installations of hundreds of megawatts, so the wide scaling range of parabolic troughs is advantageous.
Cells and substrates adapted for concentrated sunlight are more expensive than traditional cells and backsheets, so, below some concentration (dependent on cell and substrate type), it is not worth having CPV cells. Troughs only offer moderate concentration to start with, and a trough's focus becomes less and less intense farther from the centerline of the focus [10]. Below some intensity threshold, avoiding cells in a diffuse focal edge reduces PV cost with limited electric power loss, thus reducing cost per Watt.

In addition to increasing heat loss, higher cell temperatures reduce PV cell efficiency (and thus electrical output) and also decrease cell lifetime [5]. Due to the temperature gradient needed to conduct the heat from the cell surface through the cell, the solder, and the substrate and into the coolant, the coolant under a cell has to remain cooler than the cell it is cooling. While the exact temperature difference depends on the materials used and their dimensions (and is thus not in the scope of this work), this limits the maximum fluid temperature coming into the desalination unit heat exchanger, which limits the initial temperature of the desalination unit and, through limiting the number of stages, limits the amount of fresh water produced for a given heat flow. This case of the coolant temperature at the input to the desalination subsystem being at the limit of the coolant under the cells will be referred to as "Case 1" in the receiver comparison.

\section{Boosting the Thermal-Output Temperature}

The advantage of higher seawater temperature for desalination can be gained, without higher PV cell temperature, if the cell coolant is further heated after it cools the PV cells. This can be done with seawater as coolant in an open loop or with a separate heat transfer fluid in a closed loop.

One way to boost the coolant temperature is to further heat the coolant by passing the coolant through the focus of additional thermal-only trough sections after it has cooled the CPV cells by passing through the trough sections that have PV cells. This will be referred to as "Case 2" in the receiver comparison.

An alternative temperature-boosting arrangement is to use the intense central part of a concentrator's focus for PV cells and use the less intense edges of the focus for supplemental heating of the coolant to boost the coolant temperature. This will be referred to as "Case 3 " in the receiver comparison.

Figure 1 shows these three cases with the receiver area $50 \%$ covered with CPV cells and with the coolant flow directions and temperatures indicated by the arrows. Figure 2 shows a modelled view of these cases integrated in the system under study.

A use of the diffuse edge similar to Case 3 can be found in 2 -axis concentration. In some large-focus two axis concentrators, only the central region of the focus is uniform enough to cover with CPV cells in series without current matching issues [11]. While large-focus two-axis concentrator systems can current-match by using more than one size of cell [12], Han et al. propose instead using the lessintense focal edges to superheat coolant that has already 


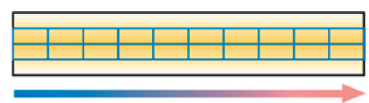

(a)

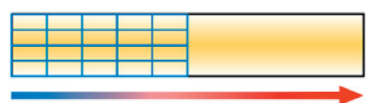

(b)

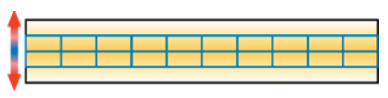

(c)

FIGURE 1: Receiver area with CPV cells, coolant flow directions, and temperatures. (a) Case 1, no temperature boost. (b) Case 2, post-CPVsection boost. (c) Case 3, edge boost.

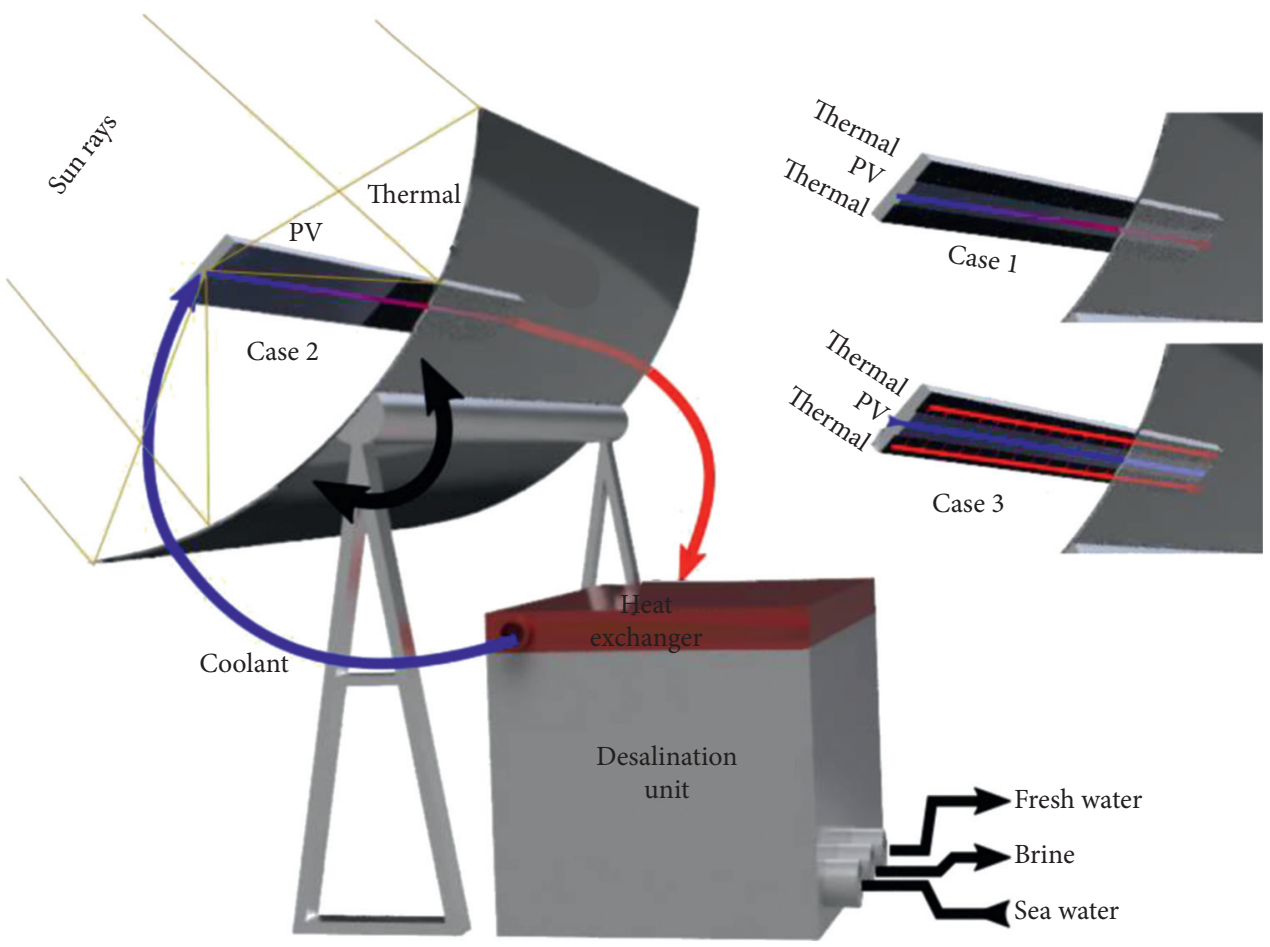

Figure 2: Modelled view (not to scale) of the different cases shown in the context of the trough mirror and desalination system.

cooled the CPV section of a receiver, with the superheated coolant then being used to generate power through an organic Rankine cycle.

While the single-axis focus of a trough also has an approximately Gaussian intensity distribution [10], a modestwidth trough can use CPV cells interconnected so that the differently illuminated regions are in parallel rather than in series, avoiding the current matching issues (wiring in parallel a set of cells that span the width of the trough's focus). However, the diffuse edges are still not optimal to cover with cells. Troughs have lower concentration than dishes or heliostat fields due to concentrating on only one axis, so a trough's concentration will more quickly fall below the threshold where it is no longer intense enough to warrant the cost of concentrator cells.

With a trough's lower concentration, the less-intense edges of the focus would have low thermal efficiency at the high heat-transfer fluid temperatures used for traditional solar thermal power generation $\left(\sim 400^{\circ} \mathrm{C},[13]\right)$, but the temperatures involved in most thermal desalination (e.g., multieffect distillation at $90^{\circ} \mathrm{C}[6]$ and even multistage flash at $120^{\circ} \mathrm{C} \mathrm{[14])} \mathrm{are} \mathrm{low} \mathrm{enough} \mathrm{that} \mathrm{thermal} \mathrm{losses} \mathrm{from} \mathrm{the}$ focal edges are low compared to the heat flux available even in these less-intense focal edges.

\section{Hybrid CPV-T Receiver Cooling Configuration}

The coolant can pass under the edges of the focus after passing under the center if it flows laterally within a receiver at the trough's focus (Figure 3). This can be accomplished by guiding the coolant to flow in a thin film or in lateral microchannels, starting under the cells at the center of the focus and ending under the thermal-only receptive area at the edge the focus. The low flow velocity and small hydraulic diameter lead to a lower Reynolds number, so the flow in a thin film or in microchannels is laminar rather than turbulent. The heat transfer into the coolant is thus through conduction within the coolant itself, and the thinner the film, the better the heat transfer coefficient for conducting the heat into the coolant and thus the better the cooling for a given coolant temperature.

With low viscosity, moderate heat conduction, high heat capacity, low cost, and low toxicity, water is a good moderate-temperature heat-transfer fluid and thus a good coolant for a CPV-T receiver. Narrow channels are not suitable for fluids that can cause fouling or scaling, so extensive pretreatment would be needed if seawater was to be heated directly. However, a closed loop with clean-water 
coolant can be used for the CPV-T receiver, and the coolant can transfer the heat to seawater through a heat exchanger. Antifreeze is often not needed in a hot region like KSA, and the small amounts of anticorrosion agent and antifouling agent (e.g., OptiShield) added to water used as coolant have little effect on the coolant's performance.

\section{Receiver Thermofluidic Description}

While the lengthwise coolant flow in Case 1 and Case 2 is suitable for turbulent flow rather than laminar flow, the cooling performance of a widthwise flowing film will be shown to be broadly similar (the flowing film can provide equal or better cooling performance, with the difference in performance small enough to ignore without affecting the conclusion).

In laminar flow heat transfer is mainly through conduction, and, with the heat transfer area not amplified by fins, the flowing film must be quite thin. While the thermal conductivity of water varies with temperature, between $50^{\circ} \mathrm{C}$ and $100^{\circ} \mathrm{C}$ is $0.66 \pm 0.02 \mathrm{~W} / \mathrm{mK}$, so a thermal conductivity of $k_{\mathrm{w}}=0.66 \mathrm{~W} / \mathrm{mK}$ is used. The center of a commercial parabolic trough's focus can reach $\sim 90 \mathrm{X}$ [15] or, to a first order, $\varphi_{t}=90 \mathrm{~kW} / \mathrm{m}^{2}$ under maximum DNI. To estimate the viable thin film thickness, we consider conduction through the film thickness, approximated as

$$
\mathrm{d} T=\frac{x \varphi_{t}}{k_{w}}
$$

Conducting this flux through each $x=1 \mathrm{~mm}$ in water would require a temperature difference of $135^{\circ} \mathrm{C}$, suggesting that significantly thinner films are required. To a first order, on average heat needs to be conducted to the middle of the flowing film, so for a film of $100 \mu \mathrm{m}$ thickness, the heat only needs to be conducted $50 \mu \mathrm{m}$ or $1 / 20 \mathrm{~mm}$, which only requires a modest temperature difference $\Delta \mathrm{T}$ of $<7^{\circ} \mathrm{C}$ at this flux of $90 \mathrm{~kW} / \mathrm{m}^{2}$ and a heat transfer coefficient of $13.3 \mathrm{~kW} /$ $\mathrm{m}^{2} \mathrm{~K}$. A more complete treatment based on the textbookcase parallel plates Nusselt number of 2.43 [16] gives $15.55 \mathrm{~kW} / \mathrm{m}^{2} \mathrm{~K}$, but the spacers that maintain the film thickness take up roughly enough area to balance that increase. The Reynolds number depends somewhat on the width and pitch of the spacers but is on the order of $\operatorname{Re}=250$, confirming laminar flow.

The thermal resistance from the cell to the coolant is generally small. A cell is only $\sim 0.2 \mathrm{~mm}$ thick and highly thermally conductive $(\sim 50 \mathrm{~W} / \mathrm{mK}$ for $\mathrm{GaAs}$ and $\mathrm{Ge}$ to $\sim 150 \mathrm{~W} / \mathrm{mK}$ for silicon), for a $\Delta \mathrm{T}$ of only $0.1^{\circ} \mathrm{C}$ to $0.4^{\circ} \mathrm{C}$ at $90 \mathrm{~kW} / \mathrm{m}^{2}$. Solder is generally also $\sim 50 \mathrm{~W} / \mathrm{mK}(70 \mathrm{~W} / \mathrm{mK}$ for SAC305 lead-free) and is typically $\sim 0.05 \mathrm{~mm}$ thick for a $\Delta T=\sim 0.1 \mathrm{C}$. The substrate is generally copper on aluminum nitride or alumina, of which only alumina has significant thermal resistance; at $\sim 25 \mathrm{~W} / \mathrm{mK}$ and typically $0.32 \mathrm{~mm}$ thick to $0.5 \mathrm{~mm}$ thick, an alumina substrate has a $\Delta \mathrm{T}=\sim 1.2^{\circ} \mathrm{C}$ to $1.8^{\circ} \mathrm{C}$. In Case 3 , a cell's temperature can thus be reasonably assumed to be no more than $10^{\circ} \mathrm{C}$ above the temperature of the coolant that cools the cell.

Case 3's heat transfer coefficient of $13.3 \mathrm{~kW} / \mathrm{m}^{2} \mathrm{~K}$ is comparable to water at that temperature flowing at $\sim 4.1$ meters/second [17] in a $66 \mathrm{~mm}$ ID pipe [15] in fully turbulent flow ( $\operatorname{Re} \sim 480,000$ ), as could be used for turbulent-flow cooling in Case 1 and Case 2. The thermal path from cell through solder through substrate is similar in all three cases, and the flowing film can avoid the heat having to pass through the wall of a coolant pipe.

Moderate pressure is sufficient to pass enough water to cool a receiver through a $100 \mu \mathrm{m}$ deep channel because the channel is as wide as the trough is long, and the distance flowed is only half the width of the trough's focus. Consider, for example, an RP3 trough (one of the most common troughs in solar thermal, also known as LS-3 or Eurotrough). With an aperture of 5.76 meters, to a first order each meter of trough can focus up to $\mathrm{dQ} / \mathrm{dL}_{\mathrm{R}}=5.76 \mathrm{~kW} / \mathrm{m}$ of optical power or $5.76 \mathrm{~W}$ per millimeter of focus, of which $2.9 \mathrm{~W}$ lands on each side of the center of the focus. If the CPV section is raising the temperature of the water by even $\Delta T_{c}=10^{\circ} \mathrm{C}$, the water absorbs $S_{\mathrm{w}}=42$ Joules $/ \mathrm{cm}^{3}$, so each millimeter of receiver needs $1 \mathrm{~cm}^{3}$ of coolant every 14 seconds. From the definition of the volumetric heat capacity, applied to a heat and liquid flow over a unit length $\mathrm{dL}_{\mathrm{R}}$ of a two-sided-flow receiver, the relation between the average coolant velocity $\left(v_{\mathrm{c}}\right)$ and channel thickness $(x)$, the coolant temperature increase $\left(\Delta T_{c}\right)$, and the incoming linear heat flux $\left(Q_{\mathrm{L}}\right)$ can be written as

$$
v_{c}=\frac{\mathrm{d} \dot{Q} / \mathrm{d} L_{R}}{2 \Delta T_{c} S_{w} x} .
$$

A $100 \mu \mathrm{m}$ thick rectangular channel would require an average coolant velocity of $70 \mathrm{~cm} / \mathrm{s}$, or $\sim 0.7 \mathrm{~m} / \mathrm{s}$, which, for water at $50^{\circ} \mathrm{C}$ in a wide channel $(>=1 \mathrm{~mm}$ wide), would have a linear pressure drop of $\sim 4.8 \mathrm{kPa} / \mathrm{cm}$. This is calculated using the classical pressure drop equation for a rectangular tube [18]:

$$
\frac{\mathrm{d} P}{\mathrm{~d} L_{c}}=2 \frac{C}{R_{e}}\left(\frac{\rho v_{c}^{2}}{D}\right)=\frac{2 C \mu v_{c}}{D^{2}} .
$$

$f=C / R_{e}$ is the friction factor of the rectangular channel (C $\sim 85$ for a $0.1^{*} 1 \mathrm{~mm}$ channel), $D$ is the hydraulic diameter of the channel, and $\mu$ is the dynamic viscosity. While the Reynolds number depends on the viscosity and thus on the coolant temperature, as noted earlier for water at $\sim 50^{\circ} \mathrm{C}$, the Reynolds number is on the order of 250 , confirming that the flow is laminar.

Flowing films can be used for a variety of receiver shapes, including cylindrical as well as flat. Consider an RP3 trough, which typically has a cylindrical receiver of $70 \mathrm{~mm}$ outside diameter [19]. With a circumference of $\sim 220 \mathrm{~mm}$, even if the coolant flowed from the center of the focus to the far backside of the receiver $(11 \mathrm{~cm})$, the pressure drop would be $\sim 50 \mathrm{kPa}$ for the flow for a $10^{\circ} \mathrm{C} \Delta T$. This is comparable to 20 meters of $66 \mathrm{~mm}$ ID pipe with $50^{\circ} \mathrm{C}$ water in turbulent flow flowing at $4.1 \mathrm{~m} / \mathrm{s}$ [17] (while $50 \mathrm{kPa}$ is already acceptably low, in laminar flow the pressure drop is proportional to the coolant velocity, which is inversely proportional to the temperature rise in the coolant, so, for a more reasonable $30^{\circ} \mathrm{C}$ temperature rise in the CPV section, the pressure drop in the receiver would only be $\sim 17 \mathrm{kPa}$ ). 
Thus, for a common commercial trough, a flowing film can provide comparably low thermal resistance and comparably low pressure drop to a turbulent low receiver. A fair comparison between the three cases can thus be made on their electrical performances and their heat byproduct temperatures.

\section{Hybrid Receiver Comparison Model}

A model was developed to illustrate the potential improvement to CPV-T from using the less-intense edges of a linear concentrator's focus to boost the temperature of coolant that has passed through a central CPV section. Three cases are compared, using the cooling for Cases 1, 2, and 3, and all with the same total receiver area and the same CPV cell area. In the first case, the CPV cells cover the full length of the receiver and part of the width, and the coolant flow is along the concentrator's focus (this is a common CPV-T receiver configuration, where the $\mathrm{CPV}$ width extends until the focus is too diffuse to justify cells). In the second case, the CPV cells cover the full width of the receiver and part of the receiver length (with thermal-only receiver for the rest of the length), and the coolant flow is along the concentrator's focus (the first way described earlier to boost the coolant's temperature after it cools the cells). In the third case, the CPV cells cover the full length of the receiver but only part of the width, where the coolant flow is laterally across the concentrator's focus (as with the flowing film embodiment detailed above).

To be applicable to a wide variety of linear concentrator types, CPV cell types, coolant ingress temperatures, and uses for the heat byproduct, several factors have been abstracted from the model, and other factors that affect all cases similarly have been simplified. While the intensity profile across a given linear concentrator's focus depends on the concentrator geometry, on the installation precision, and on the tracking accuracy, a Gaussian distribution is generally a good approximation [10], so in all cases the focal intensity is assumed to have a Gaussian distribution. The total receiver width and CPV receiver width are then specified in terms of the number of standard deviations in intensity on each side of the centerline of the focus they cover.

The coolant ingress temperature is fixed for the three cases, and the coolant flow rate for each case is defined as just sufficient to keep the hottest coolant under a CPV cell at a set temperature that is the same in each case, and the temperature rise available for use (e.g., in desalination) is expressed as the ratio of the total temperature rise to the temperature rise in the CPV section. Since the film thickness chosen provides comparable heat transfer to turbulent flow in a pipe of a reasonable size for a commercial trough, the maximum cell temperature should thus be similar in the three cases. Since the rise in coolant temperature under the CPV cells is the same, the average cell temperature is thus also similar, and the impact of temperature on cell efficiency is similar enough in the three cases that it can be ignored in this relative comparison.

For a cell temperature between $50^{\circ} \mathrm{C}$ and $100^{\circ} \mathrm{C}$, cell efficiency is typically $15 \%$ to $20 \%$ for Silicon CPV cells, $25 \%$ to $30 \%$ for GaAs cells, and $35 \%$ to $40 \%$ for triple-junction cells. The CPV cell efficiency itself cannot be abstracted out because the electrical energy that the cells export reduces the heat going into the coolant under the CPV cells, so cell efficiency affects the ratio of the total temperature rise to the rise under the CPV cells. However, the same cell type, and thus efficiency, can be used in the three cases.

\section{Results}

With the CPV cell efficiency set to $20 \%$, and with the total receiver width set to two standard deviations, the CPV cell area is varied from $0 \%$ of the receiver area to $100 \%$ (full coverage of the receiver), and the corresponding CPV cell output is calculated, along with the ratio of the total temperature rise to the rise under the CPV cells.

Two standard deviations are used as a total receiver width because it represents a reasonable $\sim 95 \%$ intercept factor for the receiver as a whole; meanwhile the optimum receiver width will vary from system to system, a narrower receiver starts to forgo a significant percentage of the concentrated light, while a wider receiver spends more area (and thus has more cost and more heat loss) to capture only a little extra energy, as shown in Figure 4.

For a given area of CPV cells, covering part of the receiver width with cells produces more electrical power than covering part of the length with cells, as shown in Figure 5, because the intense center of the focus can be covered first. However, while the standard longitudinal-flow receiver (Case 1) has the same electrical output as the lateral flow receiver (Case 3), it does not heat the coolant beyond the maximum temperature allowed under the cells, as shown in Figure 6.

While Case 2 gives higher temperature rise ratios than Case 3 for a given CPV area, that is, because it puts cells where they receive less light, less heat goes into the coolant under the cells. When the rise ratio is graphed versus electrical output (Figure 7) rather than versus cell area (Figure 6), it can be seen that Case 3 provides the same temperature rise ratio as Case 2 for the same electrical output. Thus the edge-boost Case 3 is as efficient at using CPV cell area to produce electricity as no-boost Case 1 and is as efficient at supplying heat at higher temperatures as trough-length-boost Case 2, so edge-boost provides the best of both worlds.

Consider, for example, a CPV-T system with a 2-sigma receiver $40 \%$ covered with $20 \%$ efficient cells, a coolant input temperature of $50^{\circ} \mathrm{C}$, and a maximum coolant under cell temperature of $80^{\circ} \mathrm{C}$ (e.g., a $90^{\circ} \mathrm{C}$ maximum cell temperature and a $\Delta T$ from cell to coolant of $10^{\circ} \mathrm{C}$ ). Table 1 shows the power produced relative to a receiver fully covered by PV cells. In Case 1, the receiver will produce $60.4 \%$ as much power using only $40 \%$ of the original cell surface, but, with no boost to the coolant temperature, the input to the desalination subsystem will be at $80^{\circ} \mathrm{C}$ (suitable for MED but not MSF). In Case 2, the electrical output will be only equal to the cell coverage ( $40 \%)$, but the allowable coolant temperature rise will be increased by 2.9x; the output temperature, and thus the input to the 

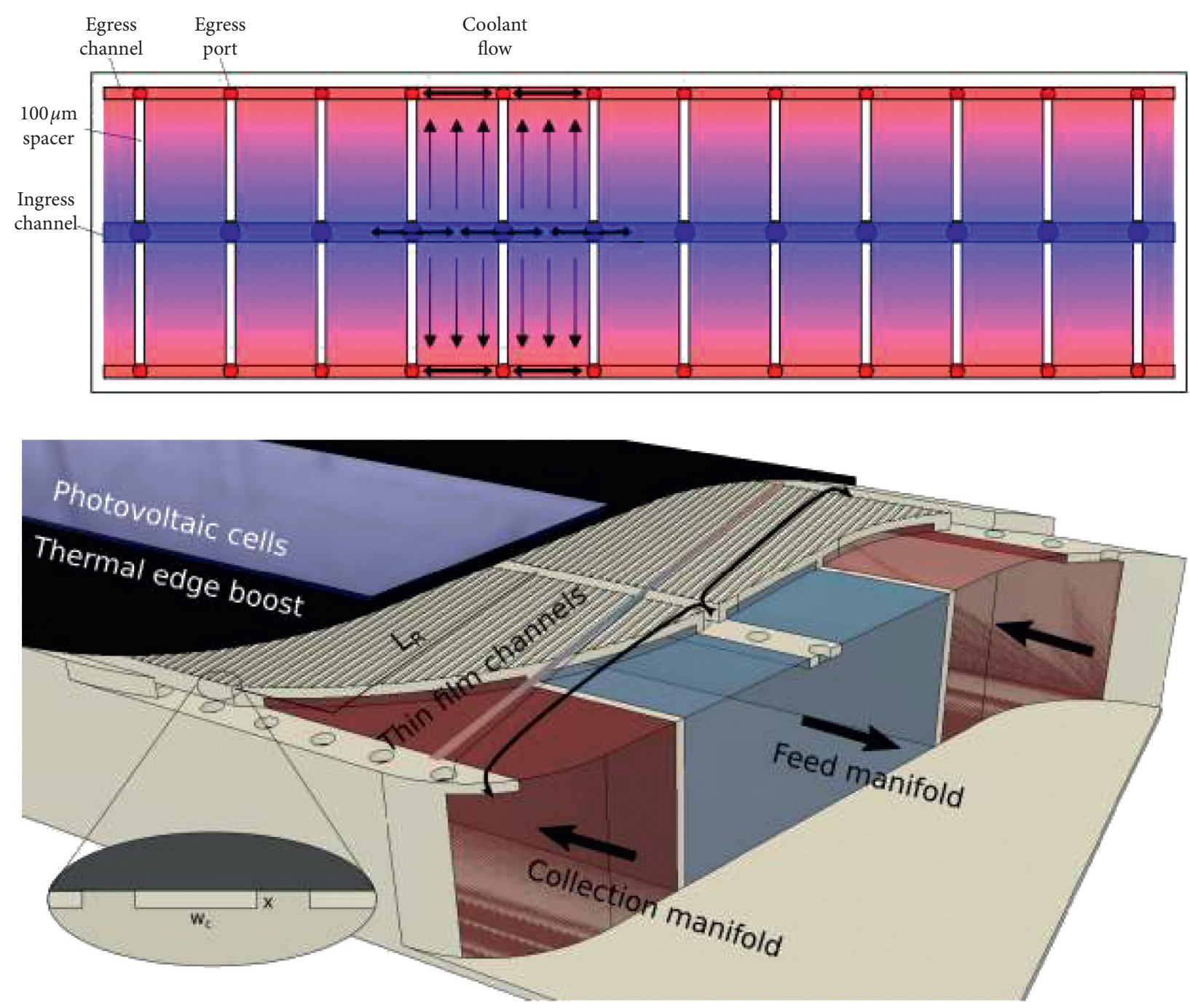

FIgURE 3: Lateral coolant flow within a CPV-T receiver.

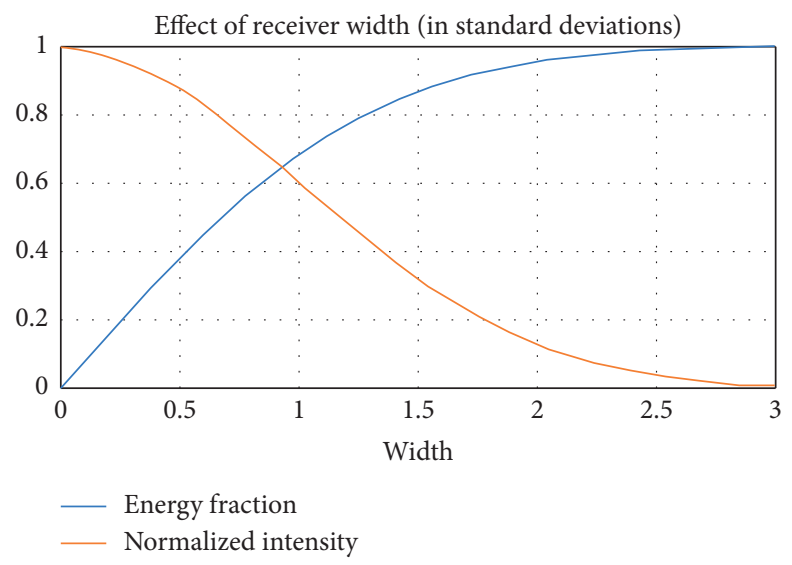

FIgURE 4: Wider receivers have diminishing returns. 


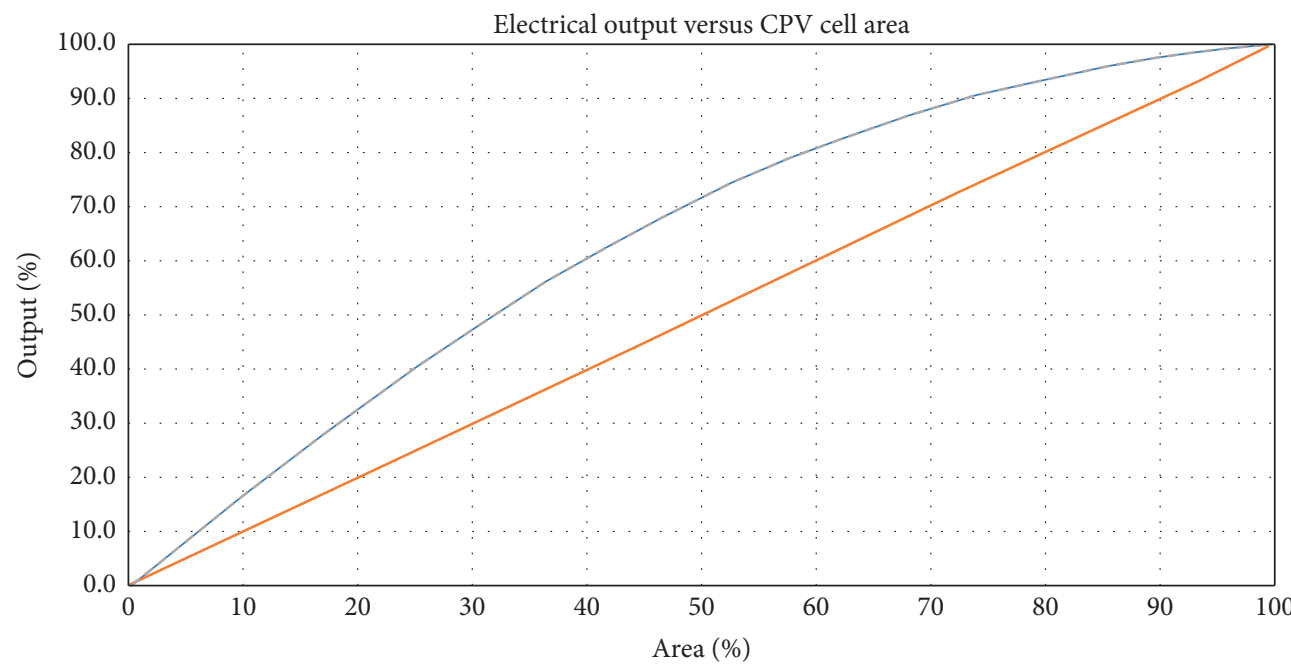

- Case 1: no post-CPV boost

_ Case 2: trough-length boost

Case 3: edge-boost (and Case 1)

Figure 5: Centralized cells produce more power per cell area.

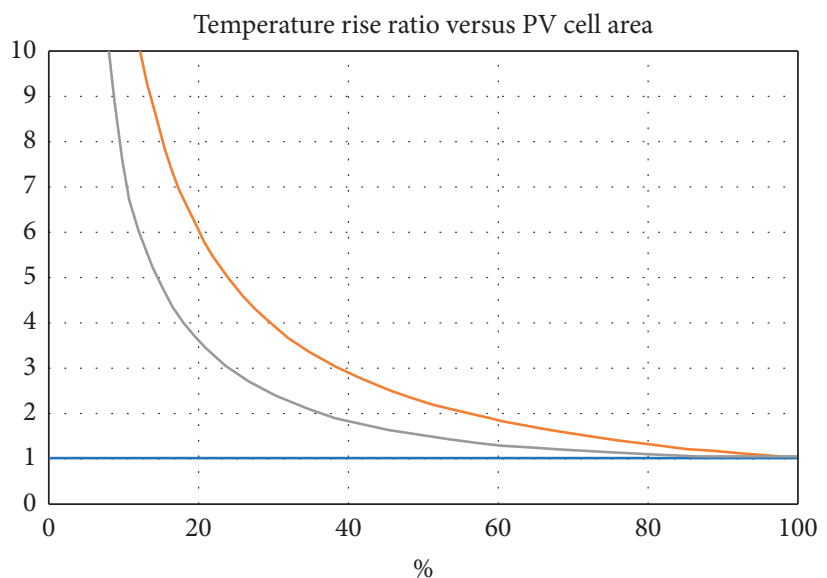

- Case 1: no post-CPV boost

- Case 2: trough-length boost

- Case 3: edge-boost

Figure 6: Temperature rise ratio versus cell coverage.

desalination subsystem, can thus be boosted to as high as $136^{\circ} \mathrm{C}$ (excessive for MED and on the high end for MSF). In Case 3, the electrical output will be $60.4 \%$ and the rise ratio of 1.82 will allow a coolant output temperature as high as $104.6^{\circ} \mathrm{C}$. If a higher temperature is desired, reducing the cell coverage in Case 3 to $24.9 \%$ can match Case 's $40 \%$ electrical output and $136^{\circ} \mathrm{C}$ coolant output while using only half the cell area of Case 2. 


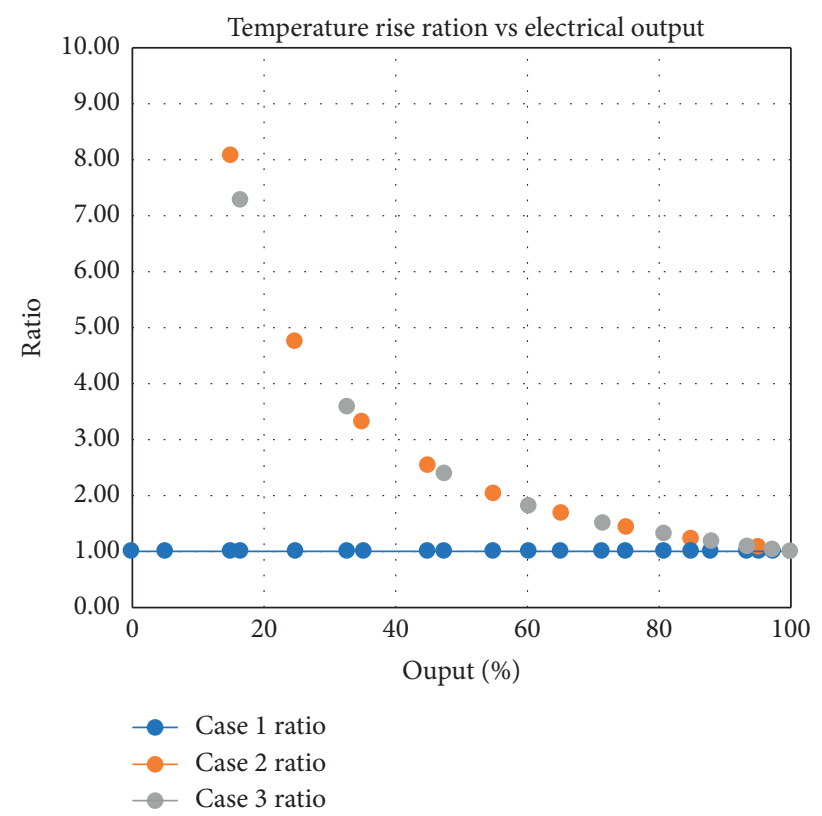

FIgURE 7: Temperature rise ratio versus electrical output.

TABLE 1: Comparison of the different cases, and their suitability for desalination, assuming the use of silicon cells.

\begin{tabular}{lccc}
\hline Case & Relative electrical power produced (\%) & Maximum coolant temperature available $\left({ }^{\circ} \mathrm{C}\right)$ & Suitability \\
\hline Case 1 & 60.4 & 80 & MED \\
Case 2 & 40.0 & 136 & MSF \\
Case 3 & 60.4 & 105 & MSF and MED \\
Case 3 (reduced coverage) & 40.0 & 136 & MSF \\
\hline
\end{tabular}

\section{Conclusions}

Parabolic-trough CPV-T is an electrical energy source that can produce heat byproduct at temperatures suitable for thermal desalination. Centralizing partial coverage with CPV cells, with lateral-flow cooling to further heat the cell coolant using the less-intense focal edges (edge-boost), provides high electrical output with high final coolant temperature to increase the value of the heat byproduct. At a given electrical output, edge-boost matches the cell area of a traditional CPV-T receiver while providing heat byproduct at a higher temperature and also matches the byproduct temperature of a post-CPV-section boost using less CPV cell area.

\section{Data Availability}

No data were used to support the findings of this study.

\section{Conflicts of Interest}

The authors declare that they have no conflicts of interest to report regarding this study.

\section{Acknowledgments}

This project was funded by the National Plan for Science, Technology and Innovation (MAARIFAH), King Abdulaziz
City for Science and Technology, the Kingdom of Saudi Arabia (Award no. 12-ENE2744-03). The authors also acknowledge with thanks Science and Technology Unit, King Abdulaziz University, for technical support.

\section{References}

[1] K. A. Rambo, D. M. Warsinger, S. J. Shanbhogue, J. H. Lienhard, and A. F. Ghoniem, "Water-energy Nexus in Saudi Arabia," Energy Procedia, vol. 105, pp. 3837-3843, 2017.

[2] S. Taha, "Kingdom imports 80\% of food products," 2014.

[3] W. Wang, S. Aleid, and P. Wang, "Decentralized Co-generation of fresh water and electricity at point of consumption," Advanced Sustainable Systems, vol. 4, no. 6, 2020.

[4] B. L. Pangarkar, M. G. Sane, and M. Guddad, "Reverse osmosis and membrane distillation for desalination of groundwater: a review," International Scholarly Research Network, vol. 2011, Article ID 523124, 2011.

[5] W. Wang, Y. Shi, C. Zhang et al., "Simultaneous production of fresh water and electricity via multistage solar photovoltaic membrane distillation," Nature Communications, vol. 10, 2019.

[6] G. Mittelman, A. Kribus, O. Mouchtar, and A. Dayan, "Water desalination with concentrating photovoltaic/thermal (CPVT) systems," Solar Energy, vol. 83, no. 8, pp. 1322-1334, 2009.

[7] C. Tzivanidis, E. Bellos, D. Korres, K. A. Antonopoulos, and G. Mitsopoulos, "Thermal and optical efficiency investigation of a parabolic trough collector," Case Studies in Thermal Engineering, vol. 6, pp. 226-237, 2015. 
[8] https://www.rackam.com/media/products/rackam_s10.pdf, accessed-2021-03-17.

[9] SolarPACES, Morocco's Noor II Begins Synchronization to Grid, SolarPACES, Almería, Spain, 2018.

[10] P. Bendt, A. Rabl, H. W. Gaul, and K. A. Reed, Optical Analysis and Optimization of Line Focus Solar Collectors, Solar Energy Research Institute, Colorado Boulevard, CA, USA, 1979.

[11] X. Han, C. Xu, X. Ju, X. Du, and Y. Yang, "Energy analysis of a hybrid solar concentrating photovoltaic/concentrating solar power (CPV/CSP) system," Science Bulletin, vol. 60, no. 4, pp. 460-469, 2015.

[12] R. Löckenhoff, T. Kubera, and K. D. Rasch, "Water cooled TJ dense array modules for parabolic dishes," AIP Conference Proceedings, vol. 1277, p. 43, 2010.

[13] J. Bhutka, J. Gajjar, and T. Harinarayana, "Modelling of solar thermal power plant using parabolic trough collector," Journal of Power and Energy Engineering, vol. 4, no. 8, pp. 9-25, 2016.

[14] P. Compain, "Solar energy for water desalination," Procedia Engineering, vol. 46, pp. 220-227, 2012.

[15] M. Islam, P. Yarlagadda, and A. Karim, "Effect of the orientation schemes of the energy collection element on the optical performance of a parabolic trough concentrating collector," Energies, vol. 12, no. 1, 2019.

[16] D. Mackowski, “Solutions to textbook questions," 2010, http:// www.eng.auburn.edu/ dmckwski/mech7220/mech7220hw2-solns.pdf,Auburn/University.

[17] Duratherm's online Heat Transfer Coefficient calculator, https://durathermfluids.com/resources/calculators/heattransfer-coefficient/accessed-2021-04-04.

[18] F. M. White, Fluid Mechanics, McGraw-Hill, New York, NY, USA, 7th edition, 2011

[19] E. Lüpfert, E. Zarza-Moya, M. Geyer et al., "Eurotrough collector qualification complete - performance test results from PSA," in Proceedings of the 2003 ISES Solar World Congress, Göteburg, Schweden, June 2003. 